\title{
Overview in the management of persistent cough in paediatric practice
}

\author{
Abstract \\ Persistent (Chronic) cough is a major psychosocial economic health burden showing \\ increased prevalence in the past18 years from $8 \%$ to $21.25 \%$ between 1999 to $2017 .{ }^{1-3} \mathrm{We}$ \\ aimed at highlighting the burden on society and effecting the quality of life. We prepared \\ recommendations based on expert opinion using few parameters like \\ a. When do we consider cough is persistent (Chronic) \\ b. What is the burden on child, family and society. \\ c. How to evaluate the child with Chronic cough \\ d. When to submit the child for investigations. \\ e. What are the common causes for persistent cough. \\ f. Does children need cough suppressants while awaiting for the diagnosis. \\ We kept social determinants, public education and cost containment in mind while preparing \\ the recommendations.
}

Keywords: chronic cough, cough medicines, environment cough, allergic cough
Volume I Issue 4 - 2018

\author{
Paramesh H,' Rashmi C Paramesh ${ }^{2}$ \\ 'Department of Pediatric Pulmonologist, Lakeside Centre for \\ Health Promotion / Lakeside Education Trust, India \\ ${ }^{2}$ Department of Physician, Lakeside Centre for Health \\ Promotion / Lakeside Education Trust, India
}

Correspondence: Paramesh H, Department of Pediatric Pulmonologist, Environmentalist, Lakeside Centre for Health Promotion / Lakeside Education Trust, Bangalore, India, Email drhparamesh@gmail.com

Received: May 28, 2018 | Published: July 06, 2018

\section{Introduction}

Cough is a protective reflex reaction to mechanical, inflammatory or chemical irritation of respiratory tract and a social signal as well. Cough receptors also present in nose, paranasal sinuses external ear, parental plural, oesophagus, stomach, diaphragm, and pericardium. Normally one can expect cough 10-11 episode per day and it can range up to 34 times. Most of them are dry cough which does not disturb sleep. After a bout of viral upper respiratory infection (URI) the cough receptors are hypersensitive for 21 days where innocuous stimulus can trigger cough which reaches its peak in 10days and later reducing to baseline by 21 days where only noxious stimuli will trigger cough. ${ }^{1}$

\section{When do we call persistent cough?}

The classification of cough as persistent (Chronic) is based on duration of symptoms and varies in different countries, between 2 weeks to 8 weeks. For example it is 8 weeks for British thoracic society, 4 weeks for American College of Chest physicians, Australia and New Zealand, 3 weeks in Belgium, 2 weeks for American academy of allergy asthma and immunology, Indian academy of paediatrics, Paediatric association of India and Nation tuberculosis association India. We considered any cough more than 2 weeks duration as persistent (Chronic Cough).

\section{What is the burden of Persistent Cough? '}

Persistent cough has a great impact on psycho-socio-economic burden on child and health care providers as shown in Table 1

The prevalence of persistent cough is observed $8 \%$ in 1999 and increased to $21.25 \%$ in 2017 in $18 y r s$.

Traffic police personnel suffer more than non-traffic police personnel $27 \%$ to $14.7 \%$ respectively
Table I Health care provider

\begin{tabular}{ll}
\hline Impact on Child & Parents \\
\hline Insomnia & Frustration \\
Exhaustion & Sleepless nigh \\
School absenteeism & Upset \\
Nausen vomiting & Stress \\
Rectal prolapse & Helplessness \\
Faecal soiling & Feeling sorry \\
Sub conjunctive haemorrhage & Frequent visit to doctors \\
Hernia & Financial burden \\
Cerebral hypoxic encephalopathy & Quality of life \\
Cough syncope & \\
Quality of life & \\
\hline
\end{tabular}

\section{How to evaluate?}

Detail clinical history and examination is paramount importance in the evaluation which includes evaluation of symptoms and signs suggestive of underlying respiratory or systemic diseases for specific pointers. The following pointers like type of cough, (dry or wet), type of sputum, timing of cough, onset and progression family history, socio environmental history and ask question for comorbidities like snoring, mouth breathing, hyperhyidrosis, grinding of teeth (bruxism) and relation to emotional stress like crying, laughing, shouting and physical exercise. Where it tickles before coughing. What medicine he is taking. Feeling of tickling sensation for cough at glottic and supra glottic area is mainly from upper airway pathology and infraglottic and supra sternal area is mainly from lower airway pathology. The physical examination should be thorough from head to toe. For early 
clubbing, ear, nose throat, neck, chest, and growth pattern. If there are any red flag signs we can subject the patient for investigation as listed in Table 2 .

Table 2 Red flag signs for investigation

\begin{tabular}{ll}
\hline $\begin{array}{l}\text { Neonatal onset cough } \\
\text { Family history lung disease }\end{array}$ & $\begin{array}{l}\text { Wet cough with focal signs in } \\
\text { chest } \\
\text { Clubbing } \\
\text { Sudden onset of cough }\end{array}$ \\
$\begin{array}{l}\text { Hemoptysis } \\
\text { Cough while feeding with dysphagia } \\
\text { and vomiting }\end{array}$ & Whidor \\
Night sweats & \\
Poor weight gain & \\
\hline
\end{tabular}

\section{How to evaluate?}

The algorithm will guide when to investigate and what are the usual investigations and special investigation is our area Figure 1.
Only $8 \%$ of the children needed special specific investigations.

\section{The causes of persistent cough}

In our study it was Lower airway allergy, asthma in 1999 but it is allergic rhinisinsities (ARS) in 2017.,3 the details are shown in Table 3. I need to mention about psychogenic cough (somatic cough) the prevalence somatic cough was $1.05 \%$ in 1999 and it has increased to $2.8 \%$ in 2017 in our practice. The American College of Chest physicians CHEST-2015. ${ }^{5}$ Recommended that the word psychogenic coughs should be changed to somatic cough from July 2018. The new terms somatic (psychogenic), Tic (Habit) cough we do accept while keeping the time tested clinical clues in the diagnosis. The Tussiphonography shows specific single diamond with absent second diamond as reflects with other cough is shown in Figure 2 \& Figure 3 clinically suspect and give supportive, behaviour modification before submitting for detail investigation for cost containment. We believe evidence based medicine is always a complimentary to experience and expertise. Art of practice of medicine cannot be replaced by alter of technology.

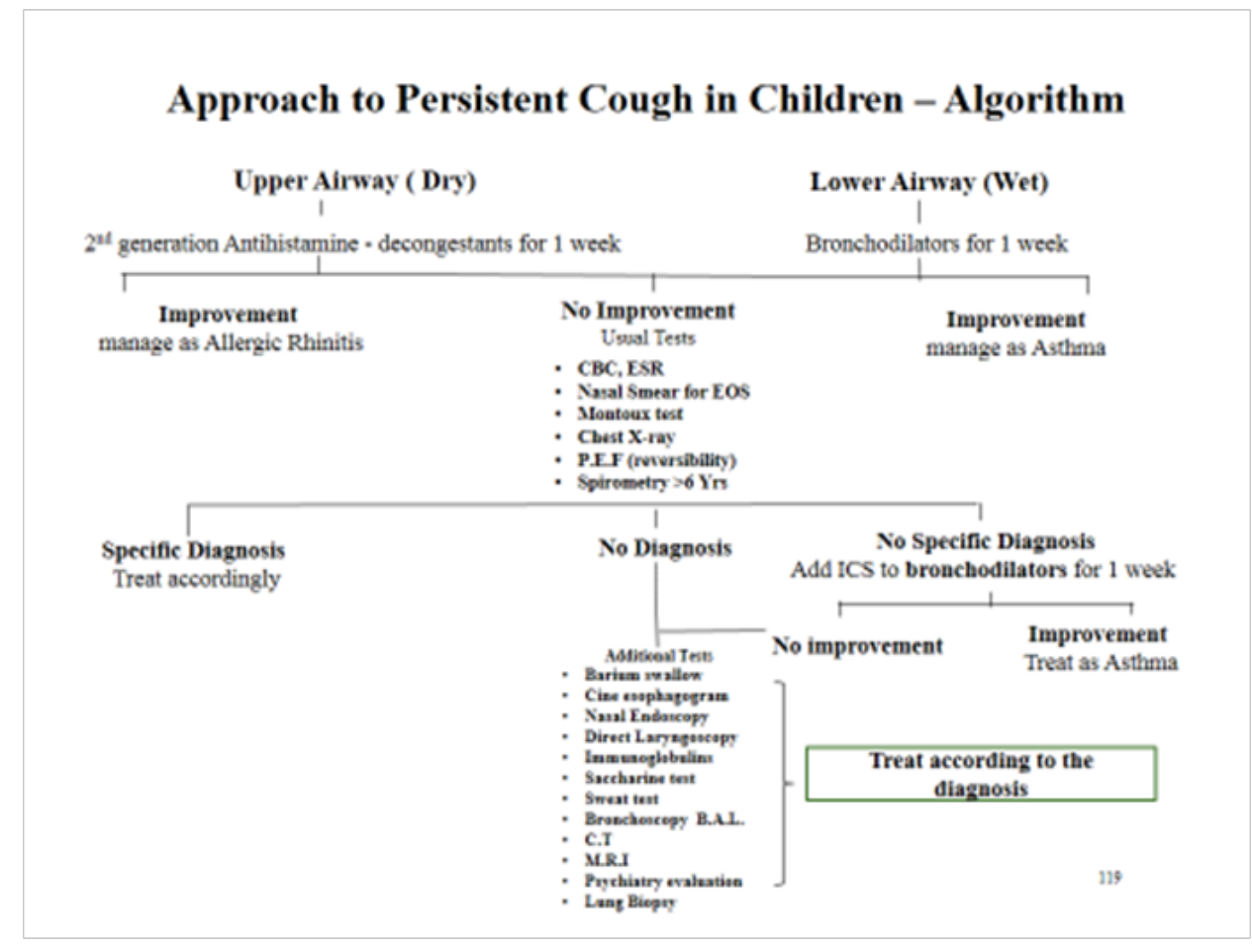

Figure I Approach to persist cough in children algorithm.

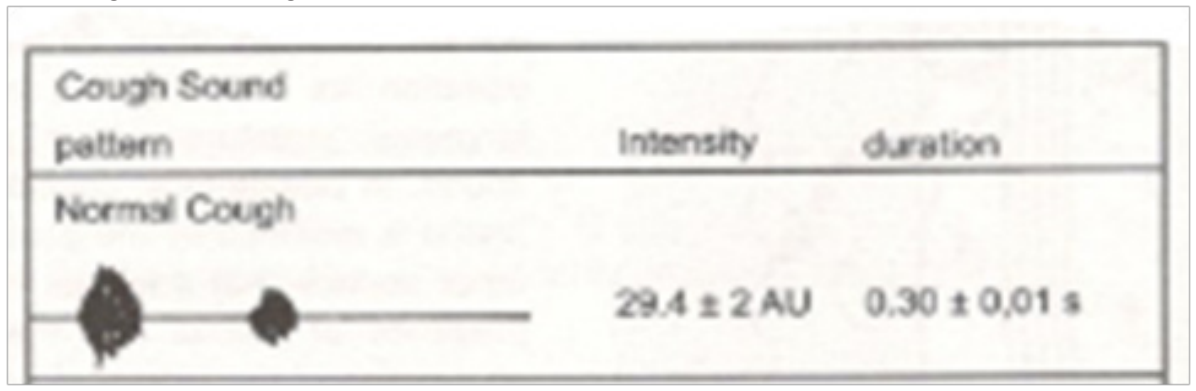

Figure 2 Tussiphonography of normal cough showing $\left.\right|^{\text {st }}$ diamond for opening of the glottis and $2^{\text {nd }}$ diamond closing of the glottis. 


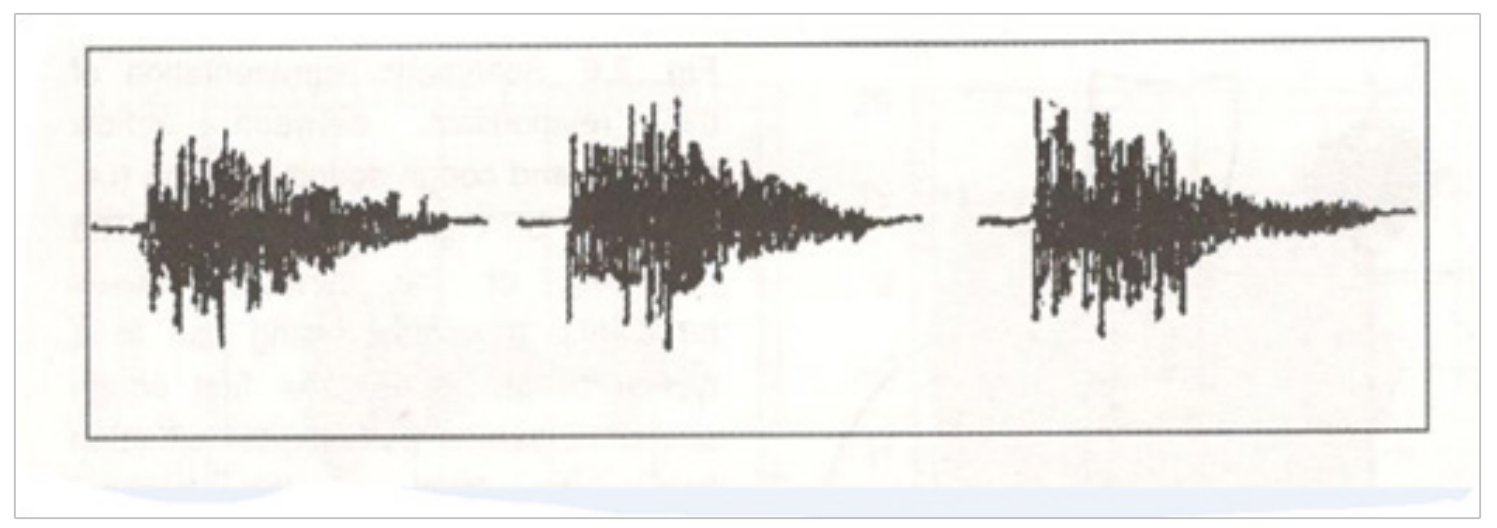

Figure 3 Somatic cough showing single diamond of 3 different patients where $2^{\text {nd }}$ diamond is absent.

Table 3 Causes of persistent cough ${ }^{1,3,4}$

\begin{tabular}{llll}
\hline I 999(no: 38I) & & 20I7(no: I 53) & \\
\hline Astama & $79.21 \%$ & Astama & $45.28 \%$ \\
ARS & $10.52 \%$ & ARS & $70.25 \%$ \\
Pneumonia & $2.09 \%$ & Asthama+ARS & $12.27 \%$ \\
Pertussis Syndrome & $2.09 \%$ & Pertussis Syndrome & $2.80 \%$ \\
Bronchiectesis & $1.05 \%$ & Bronchiectesis & $2.80 \%$ \\
$\begin{array}{l}\text { Stomach } \\
\text { cough(Psychogenic) }\end{array}$ & $1.05 \%$ & $\begin{array}{l}\text { Stomach } \\
\text { cough(Psychogenic) }\end{array}$ & $2.80 \%$ \\
$\begin{array}{l}\text { Foreign body } \\
\text { Hyper-eosinophilic }\end{array}$ & $0.53 \%$ & PBB & $0.65 \%$ \\
$\begin{array}{l}\text { Pulmonary } \\
\text { Syndrome Bronchogenic }\end{array}$ & $0.26 \%$ & & \\
Ca & $0.26 \%$ & & \\
Impacted cerumen & $0.26 \%$ & & \\
Tuberculosis & $0.26 \%$ & & \\
\hline
\end{tabular}

\section{Does Children need cough suppressents? If so what to} use

Most of the expert panel guidelines recommend not being use cough suppressants, especially in wet cough, the central antitussives are recommended only in early onset pertussis, in hemoptysis, postsurgery, dry cough with sleep disturbance, painful cough. Time has come to change our opinion to suit the burden and comorbidities involving persistent cough. This helps minimise the sleep disturbance and discomfort in the child. If child sleeps, parents can rest, grand parents can relax and primary physician can put at ease. So cough suppressants are needed while waiting for the diagnosis just like using antipyretics in febrile illness.

\section{The pertinent choice of antitussives available'}

1) Central antitussives-Codeine (Opioid) depresses respiratory center, causes dependence, decreases ciliary activity, increases bronchospasm and constipation. Not recommended in pediatric age
2) Dextromethorphan-Does not have opioid side effects, any dependency but releases histamine and not recommended allergic cough and asthma.

3) Peripheral Antitussive is-antihistamines, anticholinergic guaifenesine and benzoate.

The most promising peripheral antitussive drug is Levodropropizine a levoisomer of Dropopazine. It is a non-opioid antitussive, works at C fibre receptors on the surface of the epithelium, inhibits the release of neuropeptides and reduces the intensity frequency and night awakenings

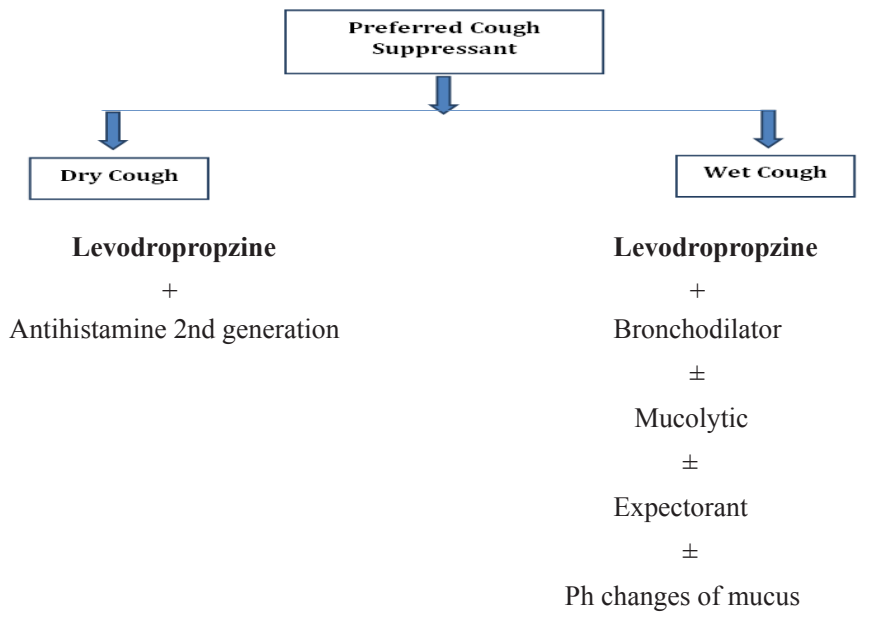

Please note recently some anaphylactic reaction is observed for levodropropzine in Korea. ${ }^{6}$

\section{Non Pharmacological recommendation are'}

a) Use of honey which coats the exposed pharyngeal ' $\mathrm{C}$ ' fibre nerve endings decreases irritation and useful in nonspecific cough

b) Warm water to drink which decreases the gustatory reflex an observational experience

c) Vaporub, menthol in cough with upper respiratory infection in infants where it gives restful night to infants. 


\section{Conclusion ${ }^{1,7,8}$}

i. Chronic cough is a major psychosocoeconomic health burden

ii. Systematic clinical evaluation contributes $92 \%$ in the diagnosis

iii. Special diagnostic tests are needed in $8 \%$ of the children with red flag signs

iv. Always here the sound of cough active or passive (by tickling the trachea, which helps in locating the site of pathology

v. Allergic airway diseases are the major cause for chronic cough. The upper airway allergy is superseded the lower airway allergy in 18 years

vi. Art of medicine should not be sacrificed at the altar of technology

vii. The evidence based medicine is always complimentary to our experience and expertise

viii. Encourage environmental control to minimise the irritation of cough receptor

ix. Social determinants dictate terms for cough suppressants while awaiting for proper diagnosis

x. Keep indoor plants which are natural air purifiers like firn, anthurium, bamboo, chrysanthemum, money plant but expose them to sun light and remove tray of water weekly.

\section{Acknowledgements}

None.

\section{Conflict of interest}

Authors declare that there is no conflict of interest.

\section{References}

1. Paramesh H, Nimain C Mohanty, Remesh Kumar, et al. Airway Disease Education \& Expertise (ADEX) NEXT Working Group Recommendations-Persistent (Chronic) Cough in Pediatric Practice. New Indian Journal of Pediatrics. 2018;6(4):230-243.

2. Chang AB, Van Asperen PP, Glasgow N, et al. Children with chronic cough: when is watchful waiting appropriate? Development of likelihood ratios for assessing children with chronic cough. Chest. 2015;147(3):745753.

3. H Paramesh, Rashmi C Paramesh. Changing spectrum and causes for chronic cough in children; 2017.

4. Paramesh H, Kabra S. Evaluation of Cough in children. Pediatrics Today. 1999;2:479-483.

5. Anne E Vertigan, Mohammad H Murad, Tamara Pringshemic, et al. Somatic Cough Syndrome (Previously Referred to as Psychogrnic Cough) and Tic Cough (Previously Referred to as Habit Cough) in Adults and Children, CHEST Guideline and Expert Panel Report. Chest. 2015;48(1):24-31.

6. Rembert Pieper, Quanshun Zhang, David J Clark, et al. Proteomic view of interactions of shiga toxin-producing escherichia coli with the intestinal environment in gnotobiotic piglets. Plos One. 2013;8(6):e66462.

7. Paramesh H, Nagaraju K, Sukumaran T, et al. Airway Diseases Education and Expertise (ADEX) in Pediatrics: Adaptation for Clinical Practice in India. Indian Pediatr. 2016;53(2):154-158.

8. H Paramesh. Air Pollution and Allergic Airway Diseases: Social Determinants and Sustainability in the control and prevalence. Indian $J$ Pediatr. 2018;85(4):284-294. 